\title{
Effect of nitrogen plasma immersion ion implantation on surface electrical breakdown strength of the aluminized polyimide
}

\section{Efeito da implantação iônica por imersão em plasma na rigidez de ruptura elétrica de superfície da poliimida aluminizada}

André Ricardo Marcondes ${ }^{1}$, Mario Ueda ${ }^{1}$, José Oswaldo Rossi ${ }^{1}$

\section{ABSTRACT}

To date, there are relatively few studies on polymer applications in space, especially those related to the evaluation of the dielectric breakdown resistance in the space environment. Polyimide (Kapton ${ }^{\mathrm{TM}}$ ) is extensively used in space in the thermal control of satellites but as a soft material subject to the aggressive space environment, it experiences degradation of properties during its lifetime. One property commonly affected in space is the surface electrical breakdown strength. The accumulation of charges on the surface of the Kapton occurs due to the formation of low-density hot plasma around the surface and due to the bombardment by highly energetic charged particles from space. The accumulation of charges can lead to deleterious electrical discharge on the surface of the material. In this study, aluminized Kapton, in the form of a film, has been treated by nitrogen plasma immersion ion implantation (PIII) inside a metallic tube. Mesh assisted and non-mesh assisted PIII have been tested. The influence of the ion implantation on the surface electrical breakdown strength of the treated samples has been determined using Weibull probability distribution function. The morphology of treated samples has been characterized by Atomic Force Microscopy. Results of the PIII treatment on morphology and surface electrical breakdown strength of Kapton are presented and discussed in this paper.

Keywords: Plasma immersion ion implantation; Polyimide, Breakdown strength.

\section{RESUMO}

Até o presente existem relativamente poucos estudos ligados à aplicação de polímeros no espaço, em especial os estudos ligados à avaliação da resistência de ruptura do dielétrico em ambiente espacial. A poliimida (Kapton ${ }^{\mathrm{TM}}$ ) é largamente utilizada no espaço em sistemas de controle térmico de satélites, mas sendo um material mole sujeito ao ambiente espacial agressivo, apresenta degradação de propriedades ao longo de sua vida útil. Uma propriedade comumente afetada no espaço é a rigidez superficial à ruptura elétrica. O acúmulo de cargas na superfície do Kapton ocorre devido à formação de plasma quente de baixa densidade em torno da superfície e ao bombardeamento por partículas carregadas altamente energéticas provenientes do espaço e que podem levar a descargas elétricas danosas na superfície do material. Neste estudo, Kapton aluminizado, na forma de filme, foi tratado por implantação iônica por imersão em plasma (IIIP) de nitrogênio dentro de tubo metálico. Foram utilizados os tratamentos por IIIP com e sem o uso de tela metálica. A influência da implantação iônica na rigidez superficial à ruptura elétrica das amostras tratadas foi determinada utilizandose a função de distribuição de probabilidade de Weibull. A morfologia das amostras tratadas foi caracterizada por meio da Microscopia de Força Atômica. Os resultados do tratamento IIIP na morfologia e na rigidez superficial à ruptura elétrica do Kapton são apresentados e discutidos neste artigo.

Palavras chave: Implantação iônica por imersão em plasma; Poliimida; Resistência de ruptura.

${ }^{1}$ Instituto Nacional de Pesquisas Espaciais - Coordenação dos Laboratórios Associados - Laboratório Associado de Plasma - São José dos Campos (SP) - Brazil Correspondence author: André Ricardo Marcondes - Instituto Nacional de Pesquisas Espaciais - Coordenação dos Laboratórios Associados Laboratório Associado de Plasma - Av. dos Astronautas, 1.758 - Jardim da Granja, CEP 12227-010 - São José dos Campos (SP) - Brazil E-mail: andre.marcondes@inpe.br

Received: 11/08/2017 Approved: 22/11/2017 


\section{INTRODUCTION}

Kapton $^{\mathrm{TM}}$ (trademark of DuPont) is the most known polyimide film. Kapton is a polymer that has been used for many years in a great variety of applications due to its outstanding and unique properties. The combination of its properties makes Kapton ideal for use in harsh environments. In space technology, thermal blankets are vital for regulating the temperature of satellites. The blankets usually consist of many layers of thin plastic sheets with aluminized Kapton as the outer layer, which is employed to absorb/reflect the right quantity of solar energy and, therefore, avoid overheating and overcooling in the interior of the satellite. Kapton is widely used in thermal blankets due to its high strength-to-weight ratio, good mechanical properties, excellent thermal stability, chemical inertness and suitable thermal optical properties $^{(1)}$. However, in space, Kapton is subject to several aggressive agents, including atomic oxygen, UV radiation, outgassing, energetic particle radiation, and meteoroids and debris. Prolonged exposure of the Kapton to those agents can significantly degrade its surface, therefore, affecting the thermal control performance and resulting in premature failure of the mission. The several aggressive agents in space environment affect Kapton in different ways. Energetic charged particles are present throughout the Earth magnetosphere ${ }^{(2)}$. Energetic particles, particularly from the radiation belts and from solar particle events, cause radiation damage to satellites, and many satellites have been lost and others have had significant operational anomalies due to satellite charging caused by the charge accumulation provided by the impact of energetic charged particles ${ }^{(3)}$. The energetic charged particles that impact the surface of the Kapton cause charging on the surface and in the bulk of the material. The charge accumulation can be damaging to the Kapton and eventually compromises the thermal blanket function. Potential differences appear on the surface of the Kapton due to energetically charged particle impacts, and when the potential difference exceeds a certain threshold, surface discharge happens ${ }^{(4)}$. The breakdown discharge on the surface of the Kapton causes damages in its structure and can affect other components of the satellites as antennas and on-board electronics. So, it is desirable to improve the flashover characteristic of the aluminized Kapton to turn it less susceptible to surface breakdown discharges.

It is known that the polyimides can be strongly modified by ion implantation ${ }^{(5)}$. Plasma immersion ion implantation (PIII) is an evolving technique that has been used for a long time to promote surface modification in a great variety of materials. In PIII, the samples are immersed in plasma and biased to a high negative potential in a pulsed manner. The high negative potential repels the electrons and attracts the ions present in the plasma. In this way, the accelerated ions are implanted on the surface of the material, resulting in surface mixing, modification, and even film formation, depending on the treatment conditions. In the last decades, several researchers have concentrated their attention on the surface modification of polymers using PIII. This technique has been used to improve different properties of many kinds of polymers $^{(6,7)}$, including Kapton ${ }^{(8)}$. The implantation of ions by PIII introduces impurity elements in the molecular structure of the polymer, modifying its surface properties. The electrical properties of a dielectric material can be modified due to charge accumulation on the surface and in the bulk. The implanted ions promote charge accumulation which cannot be easily balanced in a dielectric material. The formation of sites of accumulated charge leads to the creation of electric potentials. When the potential difference between two sites of charge buildup is high enough, the unwanted phenomenon of electrostatic discharge may take place. This phenomenon of electrical flashover is among the major causes of anomalies and electronic failure in spacecrafts ${ }^{(9)}$.

In this work, the PIII technique is used to promote the surface modification of the Kapton in order to improve its flashover characteristic, that is, to increase its surface electrical breakdown strength.

\section{EXPERIMENTAL}

Kapton used in this study was produced by DuPont as a thin film. The film was $25 \mu \mathrm{m}$ in thickness and metallized with a very thin layer (around $70 \mathrm{~nm}$ ) of aluminum in one side. The DuPont film was cut in samples of $50 \mathrm{~mm} \times 360 \mathrm{~mm}$, which were treated in two PIII experimental systems (3IP-LAP and 3IP-CE) reported elsewhere $\mathrm{e}^{(10,11)}$. The samples were put in the treatment chambers using a stainless steel tube $11 \mathrm{~cm}$ of diameter, $20 \mathrm{~cm}$ in length, and $2 \mathrm{~mm}$ in thickness as the sample holder. The samples were placed in the interior of the tube, which was pulsed by a high voltage pulser to produce the high-voltage glow discharge. The development of the PIII technique inside the tube is quite recent at INPE and is described elsewhere ${ }^{(12)}$. In some treatments, a stainless steel metallic grid was placed over the samples. The use of the metallic grid in the PIII treatment, called 'mesh assisted PIII', is a wellknown technique used to avoid both charge accumulation and the drop of potential across the sheath when dielectric samples are treated by PIII. The arrangements of the samples prior to the treatments can be seen in Fig. 1. The treatment conditions used in this study are shown in Tables 1 and 2 .

The surface breakdown voltages of the untreated and treated samples were measured using the experimental apparatus described elsewhere ${ }^{(13)}$ and depicted in Figs. 2 and 3.

Several specimens of the untreated sample and of the treated samples (\#1 to \#6) were placed between two electrodes separated by a distance previously known, as shown in Fig. 4 .

The voltage in the DC power supply was increased step by step up to the electric breakdown on the surface of the Kapton. After the capacitors charging at a value set previously, the closure of a manual switch allowed that pulsed voltages were applied to the samples to cause the breakdown discharge. The voltages across the two coils were measured by means of a digital oscilloscope. The breakdown voltage was obtained by the peak to peak differential 
measurement on the voltage waveforms. Several measurements were performed for each sample to take into account the statistical

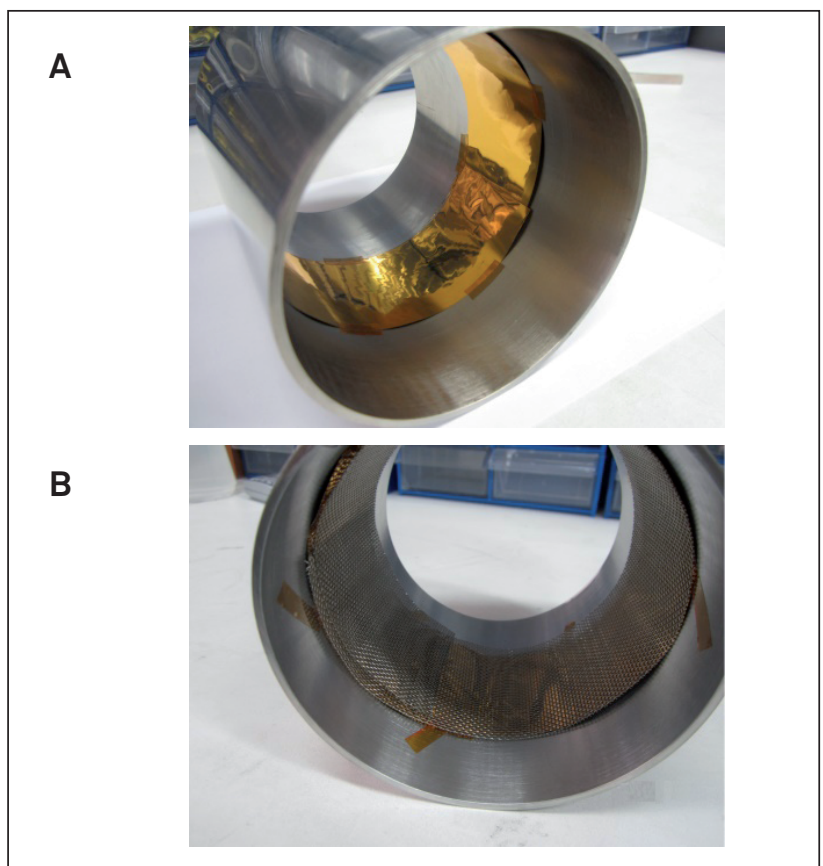

Figure 1: Kapton samples placed on the inner side of the stainless steel tube (A) without the use of the metallic grid, and (B) with the metallic grid. The polymeric side of the Kapton film was exposed to the plasma and its aluminized part was directed towards the wall of the tube. distribution of the failure. All measurements were taken at atmospheric conditions $\left(1 \mathrm{~atm}, 27^{\circ} \mathrm{C}\right)$.

Table 1: PIII processing conditions used in the treatment of aluminized polyimide film using the 3IP-LAP system ${ }^{(10)}$. In all treatments, the pulse frequency and duration were $500 \mathrm{~Hz}$ and $30 \mu \mathrm{s}$, respectively. The treatment time was $15 \mathrm{~min}$ and the working gas was nitrogen in all cases.

\begin{tabular}{|c|c|c|c|c|}
\hline Sample \# & $\begin{array}{c}\text { Pulse } \\
\text { voltage (kV) }\end{array}$ & $\begin{array}{c}\text { Pulse } \\
\text { current (A) }\end{array}$ & $\begin{array}{c}\text { Pressure } \\
\left(\mathbf{1 0 ^ { - 2 }} \mathbf{m b a r}\right)\end{array}$ & $\begin{array}{c}\text { Metallic } \\
\text { grid }\end{array}$ \\
\hline 1 & 3.0 & 2.5 & 4.2 & No \\
\hline 2 & 3.0 & 2.5 & 4.2 & Yes \\
\hline 3 & 2.5 & 1.0 & 4.6 & No \\
\hline 4 & 2.5 & 1.3 & 4.8 & Yes \\
\hline 5 & 2.5 & 2.0 & 4.4 & No \\
\hline 6 & 2.5 & 2.0 & 4.4 & Yes \\
\hline 7 & 3.0 & 5.0 & 3.6 & No \\
\hline
\end{tabular}

Table 2: PIII processing conditions used in the treatment of aluminized polyimide film using the 3IP-CE system ${ }^{(11)}$. In al treatments, the pulse frequency and duration were $1 \mathrm{kHz}$ and $30 \mu \mathrm{s}$, respectively. The treatment time was $15 \mathrm{~min}$ and the working gas was nitrogen in all cases.

\begin{tabular}{c|c|c|c|c|}
\hline Sample \# & $\begin{array}{c}\text { Pulse } \\
\text { voltage (kV) }\end{array}$ & $\begin{array}{c}\text { Pulse } \\
\text { current (A) }\end{array}$ & $\begin{array}{c}\text { Pressure } \\
\left(\mathbf{1 0}^{-2} \mathbf{m b a r}\right)\end{array}$ & $\begin{array}{c}\text { Metallic } \\
\text { grid }\end{array}$ \\
\hline 8 & 2.0 & 1.0 & 2.0 & Yes \\
\hline 9 & 1.7 & 1.5 & 3.0 & No \\
\hline
\end{tabular}

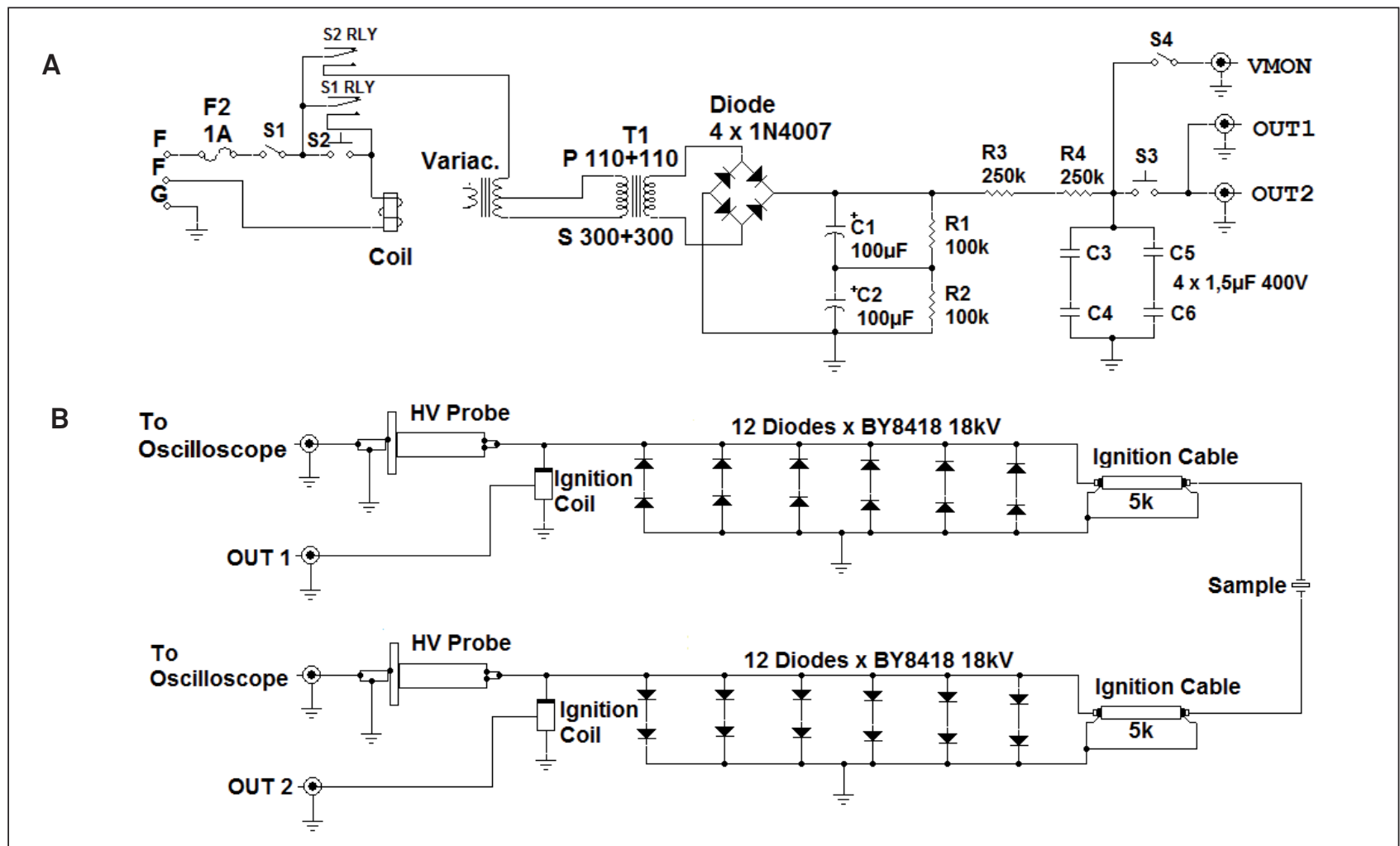

Figure 2: Electrical diagrams of the apparatus used to generate the high voltage pulses for the electrical breakdown test. (A) The primary circuit consisting of a DC power supply used to charge the capacitors $\mathrm{C} 3, \mathrm{C} 4, \mathrm{C} 5$ and $\mathrm{C} 6$, which were discharged in the ignition coils. (B) The secondary circuit consisting of two ignition coils and two reversed strings of diodes used to generate rectified high voltage pulses ${ }^{(13)}$. 


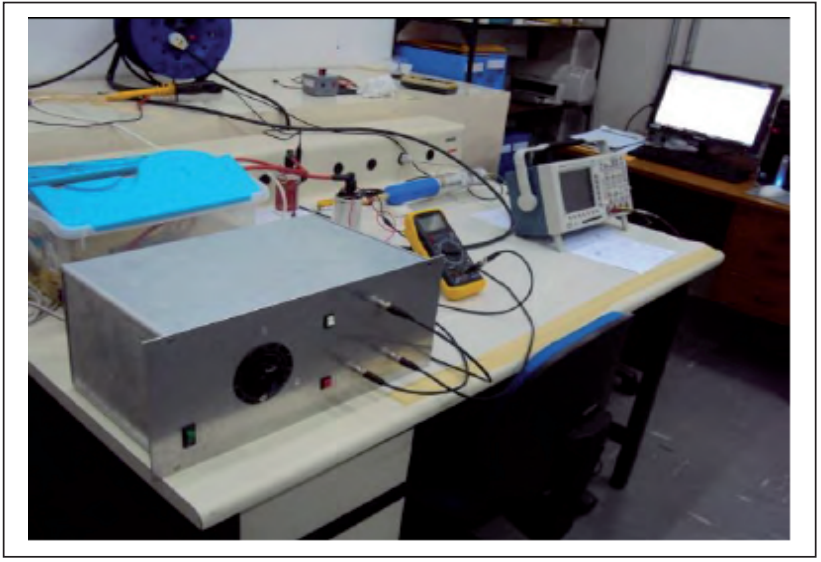

Figure 3: Photo of the experimental apparatus used for the measurement of the surface breakdown voltage of the Kapton samples. In the front of the bench, it is shown the DC charging power supply, in the back a box containing the string of diodes and ignition cables (immersed in oil) plus two ignition coils aside and the oscilloscope at right.

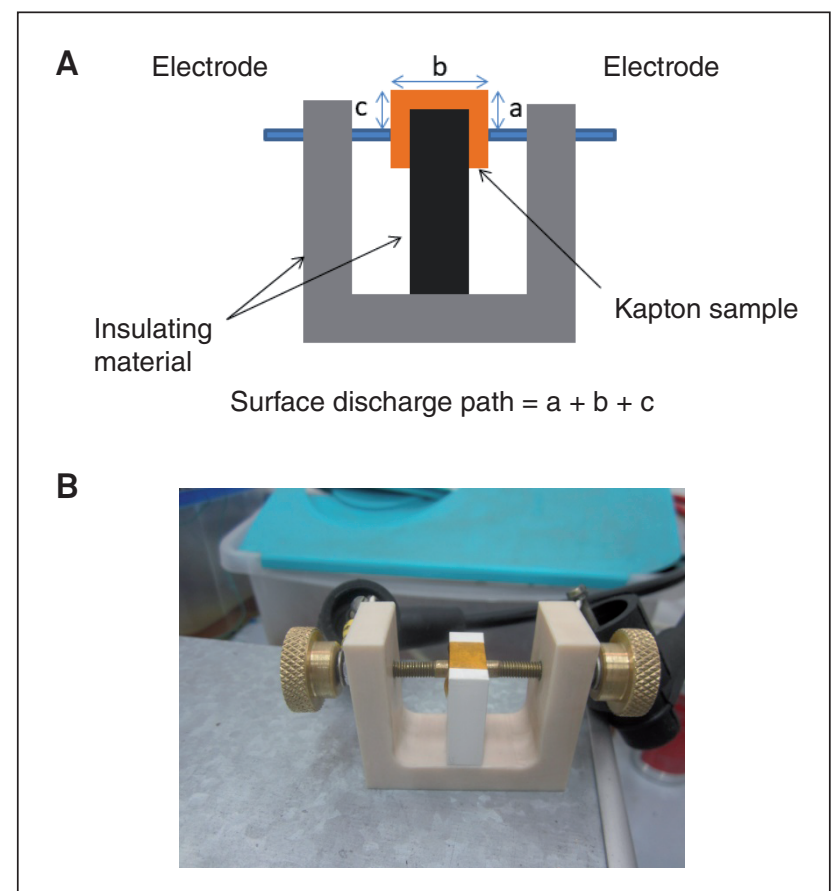

Figure 4: Schematic drawing of the sample holder used to place the Kapton sample between the two electrodes for the measurement of the surface breakdown voltage $(A)$ and its front view (B).

Atomic force microscopy (AFM) was used to characterize the morphology modification on Kapton surface due to PIII treatment. Untreated sample and samples \#7, \#8 and \#9 were analyzed by AFM using Shimadzu equipment model SPM9500 $\mathrm{J} 3$, in the tapping mode.

\section{RESULTS AND DISCUSSIONS Surface Breakdown Strength (SBS)}

The surface electrical breakdown strengths of the samples were obtained dividing the breakdown voltages by the shortest surface discharge path (see Figure 4a). Based on the work of Raju et $\mathrm{al}^{(14)}$, it was assumed that the probability of failure can be estimated using Weibull distribution function, several measurements were required for applying the statistical method to each sample. In Statistics, the use of the Weibull distribution is a reliable method to determine the probability of failure of materials due to electrical stresses. Thus, the data obtained were treated using the Weibull distribution and failure analysis. Table 3 shows the surface breakdown voltages for each specimen of untreated sample and the treated samples (from \#1 to \#6).

In Fig. 5, as an example, one can see the evolution of the breakdown voltage waveform against time for the measurement \# 1 of each sample. Although not shown herein, similar waveforms were obtained for the remaining measurements shown in Table 3.

Dividing the values of the measured breakdown voltages shown in Table 3 by the surface discharge path gives the surface breakdown strength (SBS) for each measurement of the samples according to Table 4 below.

Table 3: Measurements of breakdown voltage (kV) for each sample specimen. The number of measurements varies case to case due to unexpected failures during the testing procedure. Four measurements were considered statistically as an acceptable minimum value.

\begin{tabular}{|c|c|c|c|c|c|c|c|c|}
\hline Measurement & Untreated & $\mathbf{1}$ & $\mathbf{2}$ & $\mathbf{3}$ & $\mathbf{4}$ & $\mathbf{5}$ & $\mathbf{6}$ \\
\hline 1 & 7.2 & 15.6 & 8.9 & 7.0 & 6.2 & 10.6 & 8.0 \\
\hline 2 & 9.1 & 12.0 & 8.8 & 14.2 & 5.5 & 8.1 & 7.4 \\
\hline 3 & 7.8 & 9.7 & 9.3 & 18.0 & 6.0 & 7.5 & 7.0 \\
\hline 4 & 11.1 & 12.8 & 9.3 & 14.2 & 7.4 & 13.5 & 7.2 \\
\hline 5 & & & 8.9 & 14.6 & 6.5 & 14.1 & 8.4 \\
\hline 6 & & & & & 8.3 & 7.9 & 9.1 \\
\hline 7 & & & & & 6.0 & 5.3 & 7.4 \\
\hline 8 & & & & & & 14.5 & 9.2 \\
\hline 9 & & & & & & 16.4 & \\
\hline 10 & & & & & & 13.5 & \\
\hline
\end{tabular}

Table 4: Values of the surface breakdown strength obtained by dividing the breakdown voltages from Table 3 by the surface discharge path of $14.35 \mathrm{~mm}(\mathrm{kV} / \mathrm{mm})$.

\begin{tabular}{|c|c|c|c|c|c|c|c|}
\hline Measurement & Untreated & $\mathbf{1}$ & $\mathbf{2}$ & $\mathbf{3}$ & $\mathbf{4}$ & $\mathbf{5}$ & $\mathbf{6}$ \\
\hline 1 & 0.50 & 1.09 & 0.62 & 0.49 & 0.43 & 0.74 & 0.56 \\
\hline 2 & 0.63 & 0.84 & 0.61 & 0.99 & 0.38 & 0.56 & 0.52 \\
\hline 3 & 0.54 & 0.68 & 0.65 & 1.25 & 0.42 & 0.52 & 0.49 \\
\hline 4 & 0.77 & 0.89 & 0.65 & 0.99 & 0.52 & 0.94 & 0.50 \\
\hline 5 & & & 0.62 & 1.02 & 0.45 & 0.98 & 0.59 \\
\hline 6 & & & & & 0.58 & 0.55 & 0.63 \\
\hline 7 & & & & & 0.42 & 0.37 & 0.52 \\
\hline 8 & & & & & & 1.01 & 0.64 \\
\hline 9 & & & & & & 1.14 & \\
\hline
\end{tabular}




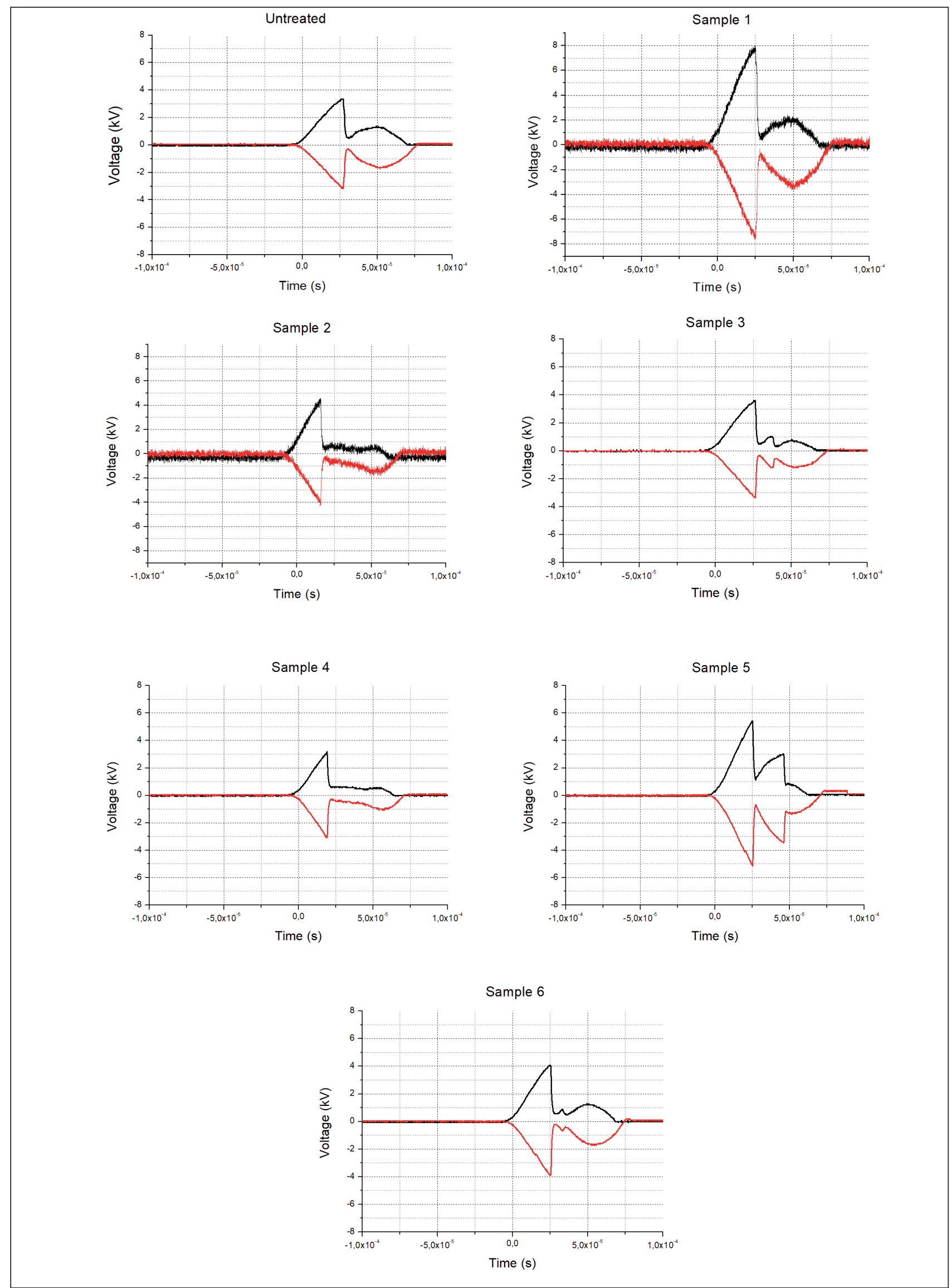

Figure 5: Breakdown voltage waveforms against time for the measurement $\# 1$ of each sample. 
To obtain the average SBS for each sample, the Weibull distribution was used, which is probably the statistical distribution more commonly used for processing and interpreting life data or time-to-failure cases. For the Weibull analysis, the cumulative failure distribution function $F(t)$ is given by ${ }^{(15)}$ :

$$
f(t)=1-\exp \left[-\left(\frac{t}{\eta_{c}}\right)^{\beta}\right]
$$

where $t$ is the time, $\beta$ is the Weibull slope (shape parameter), and $\eta_{c}$ is the characteristic life (scale parameter in which $63.2 \%$ of the products population will fail).

Now, considering $\eta$ as the random variable for the breakdown strength, the cumulative Weibull function is given by:

$$
f_{i}(\eta)=1-\exp \left[-\left(\frac{\eta}{\eta_{c}}\right)^{\beta}\right]
$$

where $f_{i}(\eta)$ is the failure probability of the sample of order with a surface breakdown strength $\eta, \beta$ is the parameter linked to the dispersion of $f_{i}(\eta)$, and $\eta_{c}$ is the real average surface dielectric breakdown, which is an unknown parameter.

One method of calculating the parameters of the Weibull distribution presented in Eq. 2 consist of using probability plotting, which means to chart the variable of interest against the cumulative percentage probability. So, the data must be ordered and the cumulative probability of each data point needs to be calculated. As $\beta$ and $\eta_{c}$ are previously unknown, the first step to determine them, based on the available data, is to linearize Eq. 2 by putting it in the form of

$$
y=a+b x
$$

In doing so, we obtain:

$$
\ln \left\{-\ln \left[1-f_{i}(\eta)\right]\right\}=\beta \ln \eta-\beta \ln \eta_{c}
$$

Comparing Eq. 3 and Eq. 4 it is obtained that:

$$
\begin{aligned}
& y=\ln \left\{-\ln \left[1-f_{i}(\eta)\right]\right\} \\
& x=\ln \eta
\end{aligned}
$$

where:

$$
\begin{aligned}
& b=\beta \\
& a=-\beta \ln \eta_{c}
\end{aligned}
$$

Next, we must rank the data to calculate the failure probability $f_{i}(\eta)$. In this case, the best rank method known is the median rank. The following approximation formula, known as Bernard's approximation, was used:

$$
\text { Median } \operatorname{rank} f_{i}(\eta)=\frac{i-0.3}{N+0.4}
$$

where: $i=$ failure order number, and $N=$ sample size.

After calculating the median $\operatorname{rank} f_{i}(\eta)$ for each failure, the measured values of the breakdown strength $(\eta)$ for each sample were put in the ascending order of magnitude and $y$ 's and $x$ 's values were obtained using Eq. 5 and Eq. 6, respectively. The set of data against were plotted using the Origin software, and the points in the chart were linearly fitted. The linear fitting provided an estimation for $a$ and $b$. Then, the values $\beta$ and $\eta_{c}$ were obtained using Eq. 7 and Eq. 8.

For example, Table 5 shows $x$ and $y$ values obtained for the untreated sample and sample \#1 using the method described previously.

In Fig. 6, the linear fittings obtained are shown after plotting $y$ against $x$ for both samples (untreated and \#1).

The average surface breakdown strength $\bar{\eta}$, for each sample can be obtained by calculating the mean of the Weibull probability distribution function given by ${ }^{(16)}$ :

$$
\bar{\eta}=\eta_{c}\left[\Gamma\left(1+\frac{1}{\beta}\right)\right]
$$

\begin{tabular}{|c|c|c|c|c|c|c|c|c|c|}
\hline \multirow{2}{*}{ Order } & \multirow{2}{*}{ Measurement } & \multicolumn{4}{|c|}{ Untreated sample } & \multicolumn{4}{|c|}{ Sample 1} \\
\hline & & $\eta(\mathbf{k V} / \mathbf{m m})$ & $\mathbf{x}(\ln \eta)$ & $r_{j}$ & $y$ & $\eta(\mathbf{k V} / \mathbf{m m})$ & $\mathbf{x}(\ln \eta)$ & $r_{j}$ & $y$ \\
\hline 1 & 1 & 0.50 & -0.68967 & 0.16 & -1.75289 & 0.68 & -0.39162 & 0.16 & -1.75289 \\
\hline 2 & 2 & 0.54 & -0.60963 & 0.39 & -0.71672 & 0.84 & -0.17884 & 0.39 & -0.71672 \\
\hline 3 & 3 & 0.63 & -0.45548 & 0.61 & -0.05027 & 0.89 & -0.1143 & 0.61 & -0.05027 \\
\hline 4 & 4 & 0.77 & -0.2568 & 0.84 & 0.60883 & 1.09 & 0.083521 & 0.84 & 0.60883 \\
\hline
\end{tabular}

where $\Gamma$ represents the Gamma function whose values are tabulated.

The standard deviation of the Weibull distribution $\sigma_{\eta}$, is given by ${ }^{(15)}$ :

$$
\sigma_{\eta}=\eta_{c}\left\{\Gamma\left(1+\frac{2}{\beta}\right)-\left[\Gamma\left(1+\frac{1}{\beta}\right)\right]^{2}\right\}^{1 / 2}
$$

Table 5: Surface breakdown strength $\eta$, median rank calculation and respective $x$ and $y$ values for each breakdown measurement of two samples (untreated and \#1). 


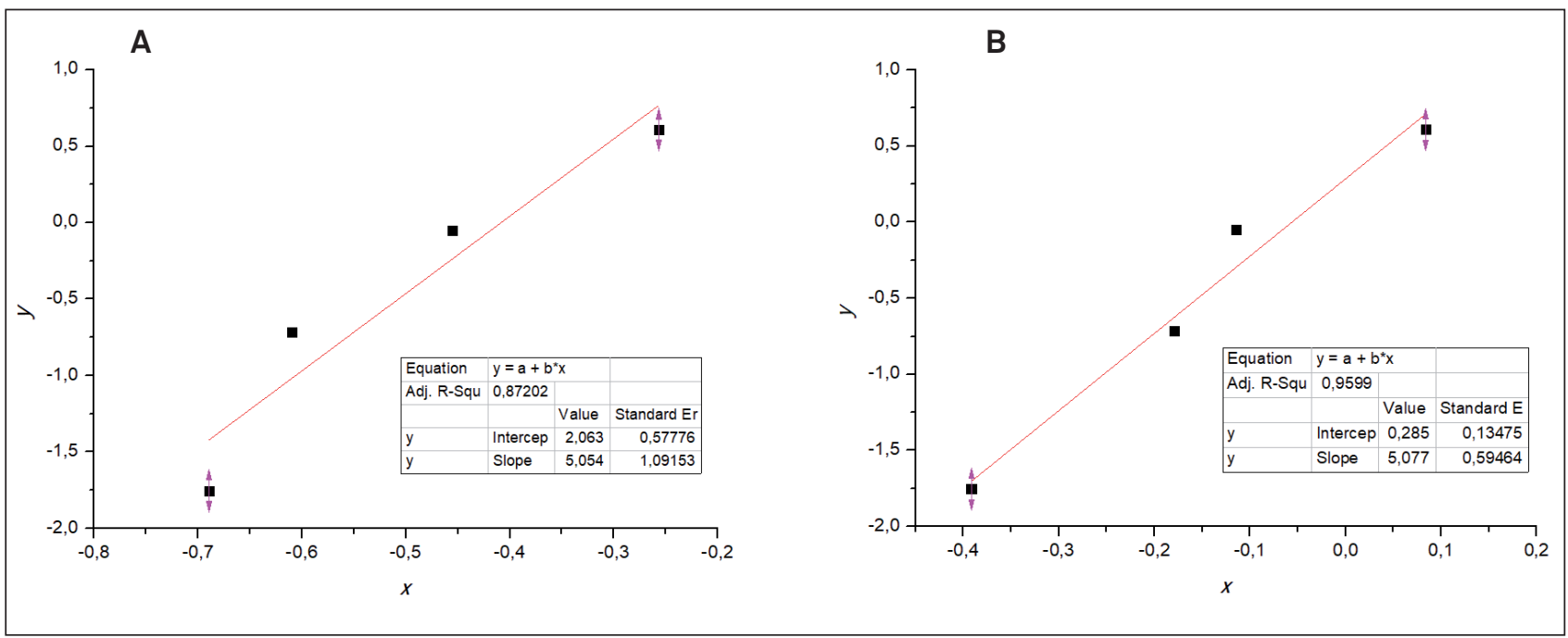

Figure 6: Linear fitting obtained for the ranked data for (a) untreated sample and (b) sample \#1. The line slope $b$, gives the value of $\beta$, according to Eq. 7, and the intercept point a gives the value of $\eta_{c}$, according to Eq. 8.

The average surface breakdown strengths and the respective standard deviations obtained for all tested samples are shown in Table 6.

The results presented in Table 6 indicate that nitrogen PIII can be advantageous to improve the SBS of the Kapton when the treatment is performed without the use of the metallic grid. Samples \#1, \#3, and \#5 were treated in this way and all these samples have shown a significant improvement in the SBS: 42, 59 , and $28 \%$, respectively, compared to the SBS of the untreated sample. However, these improvements are not observed for samples \#2, \#4, and \#6 using the metallic grid. The implantation of ions in the Kapton surface is expected to modify the polymer surface properties and recent work ${ }^{(17)}$ has shown that the use of the metallic grid during PIII of dielectric materials can increase the ion implantation energy and reduce the surface charging effect due to the decrease in the secondary electron emission. When the metallic grid is not used, the surface potential rises continuously and the potential difference between the workpiece and the plasma is reduced, causing a corresponding reduction in the energy of the implanted ions. If the implantation energies are different when the dielectric is treated with and without the metallic grid, we can expect that the structural and chemical modifications in the polymer surface will also vary between these two types of PIII treatment. Sviridov ${ }^{(18)}$ has reported that the conductivity of the implanted layer in polymers treated by ion implantation is determined by the energy of the implanted ions. So, it seems that the modification in the surface of the Kapton promoted by the PIII treatment without the metallic grid was advantageous to increase the SBS due to the implantation of less energetic ions. And the energy of the implanted ions can be correlated to the conductivity of the polymer as well to the structural and chemical modifications promoted in the surface of the polymer, which are related to the composition of the modified layer and its availability of conductive charges ${ }^{(18)}$.
Table 6: Average surface breakdown strength $\bar{\eta}$, and the respective standard deviation $\sigma_{\eta}$ obtained for untreated and treated samples using the values of the Gamma function in the points $(1+1 / \beta)$ and $(1+2 / \beta)$ according to Eq. 10 and Eq. 11, respectively.

\begin{tabular}{c|c|c|}
\hline Sample \# & $\bar{\eta}$ & $\sigma_{\eta}$ \\
\hline Untreated & 0.61 & 0.14 \\
1 & 0.87 & 0.20 \\
\hline 2 & 0.63 & 0.02 \\
\hline 3 & 0.97 & 0.40 \\
\hline 4 & 0.46 & 0.08 \\
\hline 5 & 0.78 & 0.29 \\
\hline 6 & 0.55 & 007 \\
\hline
\end{tabular}

In this work, atomic force microscopy (AFM) was used to evaluate the influence of the PIII treatments with and without the metallic grid on the surface morphology of the Kapton, complementing the above explanation of the discharge breakdown, as explained below.

\section{Atomic Force Microscopy}

The surface morphology of the untreated sample and samples $\# 7$, \#8 and \#9 were evaluated using AFM technique. The AFM images, the root mean squared (RMS) surface roughness and the surface area were treated by Gwyddion software, v. 2.47. Data were collected from surface areas of $10 \times 10 \mu \mathrm{m}^{2}$. The obtained AFM images are shown in Fig. 7.

The values of the root mean square (RMS) surface roughness, the surface area, the project area, and the ratio between the surface and the projected area are summarized in Table 7.

From Table 7 one can observe that the PIII treatment of the aluminized polyimide film has promoted a rougher surface as the RMS roughness parameter has been increased for all treated samples in comparison with the untreated one. The increase in the surface area is also noticeable for all the 


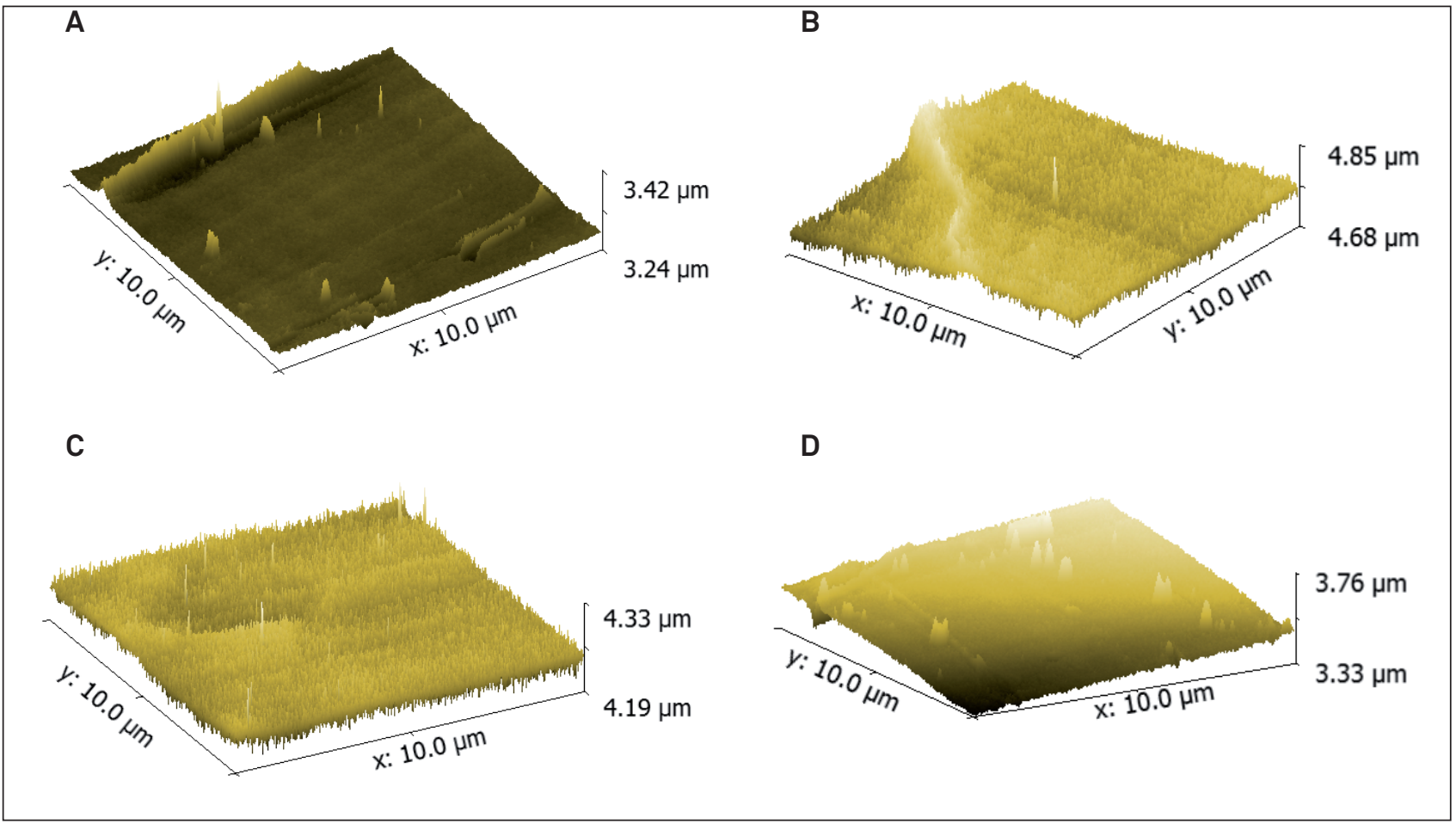

Figure 7: AFM height images of (A) untreated sample, (B) sample \#7, (C) sample \#8, and (D) sample \#9.

Table 7:Values of root mean square (RMS) surface roughness, project area, surface area, the ratio between the surface and the projected area, and the increase of area for untreated sample and samples \#7, \#8 and \#9 obtained using atomic force microscopy.

\begin{tabular}{|c|c|c|c|c|c|}
\hline Sample \# & Rms Roughness $(\mathrm{nm})$ & Projected area $\left(\mu^{2}\right)$ & Surface area $\left(\mu^{2}\right)$ & Surface area/projected area & Area increase $(\%)$ \\
\hline Untreated & 7.071 & 100.00 & 101.03 & 1.01 & 1 \\
\hline 7 & 15.59 & 100.00 & 113.39 & 1.13 & 13 \\
\hline 8 & 10.46 & 100.00 & 116.72 & 1.17 & 17 \\
\hline 9 & 15.19 & 100.00 & 107.48 & 1.07 & 7 \\
\hline
\end{tabular}

treated samples and is more evident in the samples treated without the metallic grid (samples \#7 and \#8). Even though, there are differences in the treatment conditions for samples $\#$ 7, \#8 and \#9 compared with those for the samples \# 1 to \#6, the key point is that there is a significant increase in area of the samples treated without the use of the metallic grid. This increase seems to be correlated with the increase in the SBS presented by samples \#1, \#3, and \#5, treated without the use of the metallic grid, as the AFM results indicate that the samples with the highest increase in the area have been treated without the grid, which have also presented the highest increase in the SBS.

Kapton is a dielectric material and a semi crystalline polymer with several amorphous regions. So, it is more susceptible to space charge polarization, which is the polarization associated with mobile and trapped charges. As the ion implantation goes on, more and more mobile and trapped charges are supplied to and formed in the polymer. The quantities and spatial distribution of those charged particles depend on several factors. One important factor is the energy of the implanted ions. So, the use of metallic grid during PIII treatment is expected to change the way the mobile and trapped charges are located, formed, and eventually neutralized during the ion implantation. The electrical breakdown in solids is a phenomenon highly dependent on the mobile electrons present in the material, in such a way that the quantities of electrons in the polymer surface are determinant for the electrical breakdown process. In the mesh assisted process, where a metallic grid is placed at a small distance above the sample and negatively pulsed in the same way as the workpiece, there is no electrical field between the surface of the sample and the metallic grid. In this case, despite the accumulating surface charge due to ion implantation process, the emission of secondary electron is reduced as the surface becomes more positive than the negatively biased grid and the secondary electrons generated are attracted back to the surface of the sample. So, in the mesh assisted process fewer electrons are removed from the sample when compared to the no mesh assisted process. This charge compensation may explain why better SBS was obtained with the samples treated without the use of the metallic grid and the increase in the surface area of these samples may have also contributed to the increase in the SBS by increasing the discharge path. 


\section{CONCLUSION}

Aluminized polyimide film (Kapton ${ }^{\mathrm{TM}}$ ) has been treated inside metallic tubes by means of mesh assisted and non-mesh assisted PIII technique. The surface breakdown voltages of the untreated and treated samples have been measured by applying a step by step growing voltage to the samples at atmospheric conditions. For each sample on a specific treatment condition, several specimens were measured to allow the statistical evaluation of the results. The average surface breakdown strengths for each sample have been determined using Weibull distribution function. The probability method allowed the determination of the average surface breakdown strength and respective standard deviation for each sample tested. Samples treated by non-mesh assisted PIII have shown a remarkable increase in the surface breakdown strength up to $59 \%$. This result agrees with previous work performed with nitrogen ion implantation of non-metallized Kapton ${ }^{(19)}$. Samples treated by mesh assisted PIII have shown no improvement or even some reduction in the SBS values.

The surface morphology of the untreated sample and samples treated inside metallic tube using mesh assisted and non-mesh assisted PIII technique has been evaluated using AFM diagnostic. Both PIII treatments have promoted an increase in the surface roughness and surface area of the treated samples. Samples treated by non-mesh assisted PIII have presented a higher increase in the surface area. The noticeable increase in both the surface area and the SBS of the samples treated by non-mesh assisted PIII suggest that the area increase may have been helpful to promote the increase in the SBS.

The results obtained so far are promising and indicate that the non-mesh assisted PIII may be an alternative to improve the susceptibility of the Kapton to the electrostatic charging and surface flashover in the harsh space environment.

Although the SBS results were obtained in atmospheric conditions, it is expected that in the vacuum of Low Earth Orbit $\left(10^{-8} \mathrm{~Pa}\right.$ or 0,075 Torr) the SBS of the untreated polyimide is higher than that in the atmospheric conditions. Following the same results obtained in this work, the SBS of the treated sample is expected to be higher too. The next step in this work will be to do the same measurements of the surface breakdown voltages under vacuum conditions.

\section{ACKNOWLEDGEMENT}

The main author thanks to Dr. Walter Miyakawa from Instituto de Estudos Avançados (IEAv) for his contribution in obtaining AFM images. This work has been supported by Brazilian Ministry of Science, Technology and Innovation.

\section{REFERENCES}

1. KIM, Jooheon; IM, Hyungu; $\mathrm{CHO}, \mathrm{M}$. H., Tribological performance of fluorinated polyimide-based nanocomposite coatings reinforced with PMMA-grafted-MWCNT. Wear, v. 271, n. 7, p. 1029-1038, 2011

2. ECSS-E-ST-10-04C Space engineering - Space environment

3. GARRETT, H.B., The charging of spacecraft surfaces. Reviews of Geophysics, v. 19, n. 4, p. 577-616, 1981

4. WANG, S. et al., A New Charging Model for Spacecraft Exposed Dielectric (SICCE). IEEE Transactions on Plasma Science, v. 44, n. 3, p. 289-295, 2016

5. PIVIN, J. C., Hardening and embrittlement of polyimides by ion implantation. Nuclear Instruments and Methods in Physics Research Section B: Beam Interactions with Materials and Atoms, v. 84, n. 4 , p. $484-490,1994$

6. FU, R. K.Y. et al.. Surface modification of polymeric materials by plasma immersion ion implantation. Nuclear Instruments and Methods in Physics Research Section B: Beam Interactions with Materials and Atoms, v. 237, n. 1, p. 417-421, 2005.

7. MARCONDES, A. R. et al.. Improvements of ultra-high molecular weight polyethylene mechanical properties by nitrogen plasma immersion ion implantation. Brazilian journal of physics, v. 34, n. 4B, p. 1667-1672, 2004

8. TAN, I. H. et al.. Treatment of polymers by plasma immersion ion implantation for space applications. Surface and Coatings Technology, v. 186, n. 1, p. 234-238, 2004.

9. PERRIN, C. et al.. Space charge detection in Kapton $®$ and PTFE polymer films by the open pulsed electro-acoustic method. High Performance Polymers, v. 20, n. 4-5, p. 535-548, 2008

10. UEDA, M. et al.. Plasma immersion ion implantation experiments at the Instituto Nacional de Pesquisas Espaciais (INPE), Brazil. Surface and Coatings Technology, v. 136, n. 1, p. 28-31, 2001.

11. UEDA, M. et al., New method of plasma immersion ion implantation and also deposition of industrial components using tubular fixture and plasma generated inside the tube by high voltage pulses. Review of Scientific Instruments, v. 87, n. 1, p. 013902, 2016.

12. UEDA, M. et al., Plasma immersion ion implantation (and deposition) inside metallic tubes of different dimensions and configurations. Nuclear Instruments and Methods in Physics Research Section B: Beam Interactions with Materials and Atoms, 2017

13. NETO, L.P. S; ROSSI, J. O.; SILVA, A. R., Characterization of dielectric properties of commercial ceramic capacitors for pulsed power applications. In: Power Electronics Conference (COBEP), 2011 Brazilian. IEEE, 2011. p. 347-351.

14. RAJU, G.; KATEBIAN, A.; JAFRI, S. Z., Breakdown voltages of polymers in the temperature range 23/spl deg/-250/spl deg/C. IEEE Transactions on Dielectrics and Electrical Insulation, v. 10, n. 1, p. $117-127,2003$

15. O'CONNOR, P.D.T.; O'CONNOR, P.; KLEYNER, A., Practica reliability engineering. John Wiley \& Sons, 2012.

16. KECECIOGLU, D., Reliability engineering handbook (vol. 1) Prentice-Hall, Inc., 1991

17. FU, R.K.Y.; TIAN, X.; CHU, P. K., Enhancement of implantation energy using a conducting grid in plasma immersion ion implantation of dielectric/polymeric materials. Review of Scientific Instruments, v. 74, n. 8, p. 3697-3700, 2003.

18. SVIRIDOV, D.V., Chemical aspects of implantation of high-energy ions into polymeric materials. Russian chemical reviews, v. 71, n. 4, p. 315-327, 2002

19. VERDIN, D.; DUCK, M. J., Surface modifications to minimize the electrostatic charging of Kapton in the space environment. Journal of electrostatics, v. 20, n. 1, p. 123-139, 1987 